\section{Questión}

Periodismo / Comunicación ISSN 1669-6581
- Av. $44 \mathrm{~N}^{\circ} 676,1^{\circ}$ piso

CP 1900 - La Plata - Argentina

@ www.perio.unlp.edu.ar/question

\title{
Breve relato del desarrollo del Covid-19 en Caracas
}

\section{Brief account of the development of the Covid-19 in Caracas}

\author{
Karla Perozo Olivares \\ karlaperozo@gmail.com \\ Periodista venezolana, 33 años, especialista en comunicación digital. \\ Egresada de la Universidad Católica Andrés Bello y Universidad Monteávila (Venezuela). \\ Maestranda en la Universidad Nacional de Rosario (Argentina). \\ Ha escrito para medios nacionales como Globovisión y Últimas Noticias; \\ y en portales de información como Contrapunto.com.
}

\section{Palabras Claves}

Periodismo digital - Redes Sociales - Comunicación

\section{Key Words}

Digital journalism - Social Networks - Communication

Referencia del audio: Breve relato del desarrollo del Covid-19 en Caracas, Venezuela a poco más de 100 días del confinamiento colectivo y voluntario; en medio de la crisis política y económica más fuerte de la región

\section{Enlace}

https://ar.ivoox.com/es/51717989 